Abstract P281 Table 1 Patient demographics and smoking characteristics

\begin{tabular}{llll}
\hline & $\begin{array}{l}\text { Current Smokers } \\
\mathrm{n}=24\end{array}$ & $\begin{array}{l}\text { Ex Smokers } \\
\mathrm{n}=39\end{array}$ & $\begin{array}{l}\text { Never Smokers } \\
\mathrm{n}=38\end{array}$ \\
\hline $\begin{array}{l}\text { Age } \\
\text { mean } \pm \text { SD years }\end{array}$ & $46.5 \pm 17.5$ & $55.5 \pm 23.5$ & $59.7 \pm 22.3$ \\
\hline $\begin{array}{l}\text { Male:Female } \\
\begin{array}{l}\text { Pack years } \\
\text { mean } \pm \text { SD (range) }\end{array}\end{array}$ & $21: 11$ & $11: 27$ \\
$\begin{array}{l}\text { Cannabis (\% of total) } \\
\text { Mean } \pm \text { SD Number (range) } \\
\text { of Previous Quit attempts }\end{array}$ & $12.5 \pm 2.5 \% 2.3(1-10)$ & $1.1 \pm 0.5$ range 1-3 & \\
\hline
\end{tabular}

admitted to ED in a busy inner London hospital. The views of ED doctors on the value/appropriateness of offering smoking cessation advice in ED were canvassed with the aim of defining barriers to implementation of 'right care' for sick smokers.

Methods Proforma questionnaires guided interviews of ED patients and doctors. Patient demographics, smoking history (pack years, quit attempts, motivation to quit, smoking cessation advice/referral in ED) were documented. Doctors were asked about their views on ascertaining smoking status, offering brief advice and referral to quit smoking services to smokers in ED. All patients and staff were given an information sheet explaining the purpose of the questionnaires.

Results 101 patients were interviewed. 24/101(23\%) were current smokers (3/24 12.5\% also smoked cannabis), 39/101(39\%) were ex-smokers and 38/101(37\%) were lifelong non-smokers. Table 1 demonstrates that smokers were younger than ex- and never-smokers, never-smokers were predominantly female and 17/24 (71\%) smokers had had multiple attempts to give up. In comparison, 36/39 (92\%) ex-smokers gave up on their first attempt, with 33/39(85\%) quitting without assistance. 13/24 (54\%) smokers expressed a desire to quit yet only $4(17 \%)$ were asked/given advice about smoking by a doctor. 14 doctors $(6$ FYs, 4 CMT/SPRs, 4 consultants, 8/14 had had Stop Smoking training) were questioned. 14/14 agreed that smoking cessation was important; $8 / 14(57 \%)$ felt that ED was not an appropriate place to offer advice.

Conclusion $1 / 4$ of patients attending $\mathrm{A}+\mathrm{E}$ are smokers. Over $1 /$ 2 are motivated to quit but are not offered smoking-cessation advice during admission. Despite ED staff regarding Stop Smoking as valuable treatment, there is a perception that ED is an inappropriate setting to broach the issue of quitting. Smokers tended to be younger and had multiple unsuccessful attempts to quit compared to older ex-smokers who mainly quit on the first attempt. Offering support to quit during the first attempt is the most effective way to achieve permanent cessation. ED attendance should therefore be prioritised for targeted stop smoking interventions.

\section{P282 A PROSPECTIVE STUDY TO DETERMINE THE ACCURACY OF SELF-REPORTED SMOKING HABITS IN PATIENTS WITH TUBERCULOSIS}

AL Carver, R Whiffield, MR Soobratty, GV O'Donovan, G Grove, GF Cope, HJ Milburn. King's College London, London, UK

\subsection{6/thoraxjn-2014-206260.400}

Background Smoking is an independent risk factor for tuberculosis infection, disease and mortality. It is therefore important that clinicians can identify patients who are actively smoking in order to provide optimal care. The reliability of self-reported smoking habits is often questioned but the development of biochemical assays that measure the nicotine metabolite cotinine, allow for an objective assessment of smoking status. Here we assess the accuracy of self-reported smoking habits in patients with tuberculosis by comparing these with urinary cotinine levels.

Methods Patients were recruited from two London tuberculosis clinics. Self-reported smoking habits were obtained from an interviewer administered questionnaire. Urinary cotinine levels were measured using a SmokeScreen ${ }^{\circledR}$ test kit (GFC Diagnostics, Oxfordshire, UK), a semi-quantitative colorimetric assay.

Results One hundred patients attending clinic for treatment of active tuberculosis or latent tuberculosis infection completed the study (Table 1). Nineteen reported using tobacco and had either smoked or chewed tobacco the day before testing, the quantity of which was representative of a standard day's consumption. Duration of smoking ranged from 3 to 40 years with a mean of $13.4+10.5$ and a median of 10.0. Eight further patients recorded stopping smoking between a few days and 6 years prior to testing, with a mean cessation period of $2.0+2.1$ years. Two of these had later started chewing tobacco.

Although nineteen patients reported either smoking or chewing tobacco, a further six patients' urine tested positive for cotinine, i.e. $24 \%$ of tobacco users failed to report its use (Table 1). Furthermore, nine patients produced the colour change indicating heavy smoking (11-15/day) and ten patients produced a result indicating very heavy smoking $(>16 /$ day), although only two reported smoking 11-15 cigarettes the previous day and a further two must have chewed an equivalent amount of tobacco. This corresponds to $79 \%$ of heavy to very heavy tobacco users under-reporting its use.

Conclusion Discrepancies exist between objective and subjective assessments of smoking habits amongst patients with TB which may be attributable to an under-reporting of tobacco use, suggesting further avenues of research in this patient cohort.

\section{P283 CHRONIC OBSTRUCTIVE PULMONARY DISEASE (COPD) CASE-FINDING AND TOBACCO DEPENDENCE ON LONG STAY PSYCHIATRIC WARDS}

${ }^{1} \mathrm{D}$ Hughes, ${ }^{1} \mathrm{M}$ Jeanneret, ${ }^{1} \mathrm{~F}$ Johansson, ${ }^{1} \mathrm{~K}$ Sherring, ${ }^{2} \mathrm{~L}$ Restrick. ${ }^{1}$ Camden and Islington NHS Foundation Trust, London, UK; ${ }^{2}$ Whittington Health, London, UK

\subsection{6/thoraxjnl-2014-206260.401}

Introduction and objectives $42 \%$ of UK tobacco smoked is consumed by people with mental disorders. ${ }^{1}$ Smoking prevalence, and the proportion of highly-dependent smokers, are increased in patients with severe mental illness (SMI) and smoking is the main cause of high premature mortality in this group. ${ }^{1}$ The prevalence of COPD, a disease with $>85 \%$ smoking-attributable deaths, in psychiatric in-patients is unknown and patients with SMI are less likely to have physical-health-checks and treatment. ${ }^{1}$ We hypothesised that COPD is under-diagnosed and under-treated in in-patients with SMI.

Methods Case notes review and a structured smoking/respiratory assessment, using NICE COPD guidance with spirometry/ oximetry, ${ }^{2}$ were performed for in-patients with SMI over 1 month on three long-term psychiatric wards in an inner-city mental health trust.

Results Patient demographics are shown in the Table. 
Poster sessions

Abstract P282 Table 1 Patient demographics and a comparison of self-reported tobacco use against urinary cotinine levels as determined by the Smokescreen $\circledast$ test

\begin{tabular}{|c|c|c|c|c|c|c|c|c|c|}
\hline \multicolumn{10}{|c|}{ Patient demographics $(n=100)$} \\
\hline & & \multicolumn{4}{|l|}{ Male } & \multicolumn{4}{|l|}{ Female } \\
\hline \multirow[t]{2}{*}{ Sex } & & \multicolumn{4}{|l|}{$56 \%$} & \multicolumn{4}{|l|}{$44 \%$} \\
\hline & & \multicolumn{4}{|l|}{ Mean + SD } & \multicolumn{4}{|l|}{ Median (range) } \\
\hline \multirow{2}{*}{\multicolumn{2}{|c|}{ Age }} & \multicolumn{4}{|l|}{$35.6+12.1$} & \multicolumn{4}{|l|}{$33(17-74)$} \\
\hline & & U. K. & Africa & Indian subcontinent & & \multicolumn{2}{|c|}{ South East Asia } & \multirow{3}{*}{\multicolumn{2}{|c|}{$\begin{array}{l}\text { Caribbean } \\
4 \%\end{array}$}} \\
\hline \multirow{2}{*}{\multicolumn{2}{|c|}{ Place of origin }} & $11 \%$ & $27 \%$ & $52 \%$ & & $4 \%$ & & & \\
\hline & & Before 2000 & & & & \multicolumn{2}{|l|}{ After 2000} & & \\
\hline \multirow{2}{*}{\multicolumn{2}{|c|}{ Year of entry to $\mathrm{U} . \mathrm{K}$. }} & \multicolumn{4}{|l|}{$18 \%$} & \multicolumn{4}{|l|}{$72 \%$} \\
\hline & & \multicolumn{4}{|l|}{ Mean + SD } & \multicolumn{4}{|l|}{ Median (range) } \\
\hline \multirow{2}{*}{\multicolumn{2}{|c|}{ Weight }} & \multicolumn{4}{|l|}{$65.8+10.6 \mathrm{~kg}$} & \multicolumn{4}{|l|}{$65(38-94)$} \\
\hline & & \multicolumn{4}{|l|}{ Mean + SD } & \multicolumn{4}{|l|}{ Median (range) } \\
\hline \multirow{2}{*}{\multicolumn{2}{|c|}{ Creatinine }} & \multicolumn{4}{|l|}{$65.3+15 \mathrm{~mol} / \mathrm{L}$} & \multicolumn{4}{|l|}{$63(35-103)$} \\
\hline & & $>60 \mathrm{mls} / \mathrm{min}$ & & & & $<60 \mathrm{mls} / \mathrm{min}$ & & & \\
\hline Estimated Glomerular Fil & & $100 \%$ & & & & $0 \%$ & & & \\
\hline & & Normal & & & & Abnormal & & & \\
\hline Liver function & & $96 \%$ & & & & $4 \%$ & & & \\
\hline & & No Alcohol & & & & Regular alcohol & & & \\
\hline Alcohol consumption & & $89 \%$ & & & & $11 \%$ & & & \\
\hline & & Yes & & & & No & & & \\
\hline Recreation drug use & & $2 \%$ & & & & $98 \%$ & & & \\
\hline & & Positive & & & & Negative & & & \\
\hline HIV status & & $1 \%$ & & & & $99 \%$ & & & \\
\hline Smoking history and Sm & M & & & & & & & & \\
\hline & & & SmokeScre & B $(n=100)$ & & & & & \\
\hline & & $=100)$ & Negative & Light & Moderate & & Heavy & Very heavy & \\
\hline No tobacco & 8 & & 71 & 2 & 2 & & 5 & 1 & \\
\hline Total Smokers & 1 & & 4 & 2 & 0 & & 3 & 8 & \\
\hline 1-5 Cigarettes / day & 9 & & 2 & 2 & 0 & & 2 & 3 & \\
\hline 6-10 Cigarettes / day & 6 & & 2 & 0 & 0 & & 1 & 3 & \\
\hline 11-15 Cigarettes / day & 2 & & 0 & 0 & 0 & & 0 & 2 & \\
\hline Chew tobacco & 2 & & 0 & 0 & 0 & & 1 & 1 & \\
\hline
\end{tabular}

Abstract P283 Table 1 Patient and Admission Demographics

\begin{tabular}{|r|c|}
\hline Patients (n) & 41 \\
\hline Male & 24 \\
\hline Memale & 17 \\
\hline Age (years) & \\
\hline Range & $22-78$ \\
\hline Primary SMI Diagnosis (n) & \\
\hline Schizophrenia & 31 \\
\hline Schizoaffective Disorder & 5 \\
\hline Bipolar Affective Disorder & 3 \\
\hline Other & 2 \\
\hline Casefinding Dates & April 2014 \\
\hline Length of Stay (months) & \\
\hline Mean & 26 \\
\hline Median & 16 \\
\hline Range & $2-117$ \\
\hline
\end{tabular}

34/41 (83\%) were confirmed current tobacco smokers with mean (SD) 34 (28) pack-years; 5 were non-smokers and 2 exsmokers. 24/41 (59\%) were previous/current cannabis smokers.

Quit Smoking Support (QSS) was offered to 25/34 (74\%) tobacco smokers with medication prescribed for 9/34 (26\%). Median (range) self-assessed MRC-breathlessness score was 1 (1$2) ;(\mathrm{n}=16$ and 18 did not engage). Mean (SD) oxygen saturation was $96.6(2.4) \%(\mathrm{n}=21 ; 13$ did not engage). Three smokers (9\%) had an existing diagnosis of COPD. 18/28 eligible patients had spirometry; 10 (36\%) did not engage. Mean (SD) $\mathrm{FEV}_{1}$ was $2.41(1.01) \mathrm{L} ; 4 / 18$ (22\%) were obstructive. 3/6 $(50 \%)$ smokers with COPD (1 ex-smoker) were offered QSS and 2 were referred for respiratory input.

Conclusions COPD prevalence was $17 \%$ in this in-patient group, over half of whom were undiagnosed. A third of patients declined spirometry, reflecting challenges of engagement in SMI. Nevertheless 2 in 9 tests resulted in new COPD diagnoses. Smoking prevalence was high at $83 \%$ but 1 in 5 smokers were not offered QSS, including half of those with COPD. These results support the case for respiratory-mental health collaborations during long psychiatric admissions.

\section{REFERENCES}

No health without mental health. Department of Health. 2011

2 NICE clinical guideline 101. Chronic obstructive pulmonary disease. 2010 